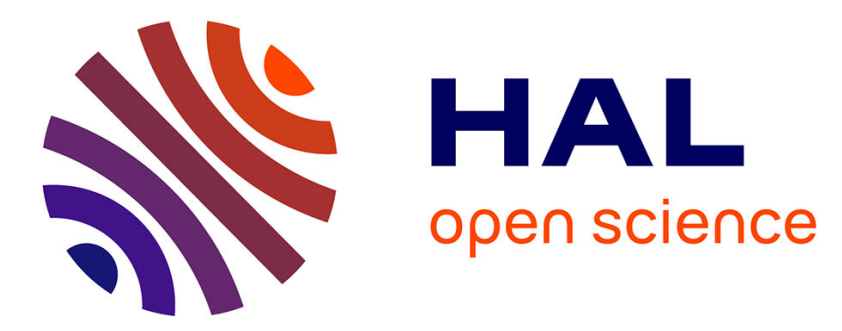

\title{
Specifying Self-organising Logistics System: openness, intelligence, and decentralised control
}

\author{
Shenle Pan, Damien Trentesaux, Yves Sallez
}

\section{To cite this version:}

Shenle Pan, Damien Trentesaux, Yves Sallez. Specifying Self-organising Logistics System: openness, intelligence, and decentralised control. SOHOMA'16 Workshop on Service Orientation in Holonic and Multi-Agent Manufacturing, Oct 2016, Lisbon, Portugal. hal-01389875

\section{HAL Id: hal-01389875 https://hal.science/hal-01389875}

Submitted on 8 Nov 2016

HAL is a multi-disciplinary open access archive for the deposit and dissemination of scientific research documents, whether they are published or not. The documents may come from teaching and research institutions in France or abroad, or from public or private research centers.
L'archive ouverte pluridisciplinaire HAL, est destinée au dépôt et à la diffusion de documents scientifiques de niveau recherche, publiés ou non, émanant des établissements d'enseignement et de recherche français ou étrangers, des laboratoires publics ou privés. 


\title{
Specifying Self-organising Logistics System: openness, intelligence, and decentralised control
}

\author{
Shenle Pan $^{1}$, Damien Trentesaux ${ }^{2}$ and Yves Sallez ${ }^{2}$ \\ ${ }^{1}$ MINES ParisTech, PSL Research University \\ Centre de Gestion Scientifique - I3 - UMR CNRS 9217 \\ 60 Bd St Michel 75006 Paris, France \\ shenle.pan@mines-paristech. fr \\ ${ }^{2}$ LAMIH, UMR CNRS 8201 \\ University of Valenciennes and Hainaut-Cambrésis \\ F-59313 Valenciennes, France \\ damien.trentesaux@univ-valenciennes.fr \\ yves.sallez@univ-valenciennes.fr
}

\begin{abstract}
This paper contributes to the development of a novel paradigm in logistics, i.e. self-organising logistics system (SoLS). A SoLS can be considered as a logistics system that can function without significant intervention by human, and without central control by software. It is functioning based on contextual local interactions. By such definition, SoLS could be a powerful solution to manage nowadays logistics that is much larger and complex than ever before. The goal of this paper is to provide a comprehensive and in-depth discussion to specify expected advantages and functionalities of SoLS, supported by some recent emerging concepts and technologies. The paper also attempts to provide a theoretical framework for the future work.
\end{abstract}

Keywords: Logistics, Self-organisation, Openness, Intelligence, Decentralised control, Holonic and Multi-Agents System.

\section{Introduction}

Nowadays logistics system is much larger and complex than ever before, and, therefore, difficult to manage as a whole. One may have heard about many emerging technologies, concepts and paradigms that are proposed as solutions to cope with this difficulty, e.g. intelligent product or intelligent logistics [1], Holonic and MultiAgents System [2], Cyber-physical System [3], or Physical Internet [4]. One may be interested in the following question: what could be the next era of logistics if all these solutions have a joint effort to develop the logistics? This paper discusses one of the possible eras, namely self-organising logistics system (SoLS hereinafter).

Self-organisation is a popular term in many research fields, for example in computer science, human society and behaviour, and biology [5-7]. However, in the field of logistics, it is still a developing paradigm. As suggested in [8], a SoLS is a logistics 
system that "can function without significant intervention by managers, engineers, or software control". The suggested definition implies some potential advantages of such systems to today's large-scale and complex logistics. Based on these works, we attempt to provide a wider and deeper vision to specify SoLS, by defining its main desired functionalities and analysing its advantages in the context of logistics organisation. The advantages are discussed qualitatively from perspectives on logistics performance and on sustainability, to illustrate that SoLS could make logistics more autonomous, efficient and effective, i.e. a more sustainable system.

For the sake of providing an overview and insightful discussion of SoLS, this paper proposes to discus several main functionalities of future SoLS: openness, intelligence, and decentralised control. Openness means that a SoLS should allow actors (e.g. shippers, service providers, or customers) or assets (e.g. trucks, containers, or warehouses) to easily join and leave the system, for the sake of fast reconfiguration. Intelligence emphasises the object-based capability of local real-time communication and activeness [9]. Decentralised control focuses on collaborative rules and communication protocols designing, i.e. environment, for SoLS. It should be noticed that decentralised control for SoLS aims to avoid unexpected or disastrous outcomes of the system, but not to optimally plan activities or control objects. Further, we will also discus expected advantages and performance of SoLS with regard to current challenges in logistics.

\section{Relevant Literature}

\subsection{Self-organisation in Logistics}

There is limited literature investigating self-organisation in the field of logistics. References [10-12] propose to consider supply network as complex adaptive system where self-organisation is considered as an internal mechanism between agents. Differently, reference [8] considers self-organisation as a organisational paradigm to cope with complex assembly lines, by using "bucket brigade" assembly lines as illustration. Other studies from the same standpoint can be found in the field of manufacturing, e.g. $[2,13]$.

This paper is in line with [8] and extended to investigate SoLS functionalities for effectiveness and efficiency, which is particular important to cope with current and future challenges in logistics, see Table 1. From our point of view, a SoLS is an open, intelligent and holonic logistics system that aims to harmonise and lead individuals within the system towards a system-wide common goal, without significant human intervention from outside. An individual within SoLS can be an object (e.g. a truck), a manufacturer, a service provider (e.g. 3PL), a receiver (e.g. a customer), even a supply chain or a supply network as a whole. Assuming that individuals may have different constraints and objectives, e.g. service rate improvement or cost reduction, we argue that SoLS should have the ability to respect individual's constraints and objectives, meanwhile leading them towards a common goal - the sustainability for exam- 
ple. To this end, individuals should be coordinated by system-wide well-designed rules, i.e. the system environment [14].

\subsection{Expected Advantages and Performance}

Based on the suggested definition, some advantages of SoLS can be expected. We here discuss qualitatively expected advantages according to six main indicators of performance measurement, as described in Table 1:

Table 1. Advantages and expected performance of SoLS functions

\begin{tabular}{|c|c|c|}
\hline & Description & $\begin{array}{c}\text { SoLS expected advantages } \\
\end{array}$ \\
\hline $\begin{array}{l}\text { Effective- } \\
\text { ness }\end{array}$ & How well a goal is adequately met? [15] & $\begin{array}{l}\text { Individuals should be able to make au- } \\
\text { tonomous decision to meet a given goal }\end{array}$ \\
\hline Efficiency & $\begin{array}{l}\text { How well the resources expended are } \\
\text { utilised? [15] }\end{array}$ & $\begin{array}{l}\text { Individuals should intelligently use the } \\
\text { on-hand resources }\end{array}$ \\
\hline Agility & $\begin{array}{c}\text { Ability of a system to rapidly reconfig- } \\
\text { ure [16] }\end{array}$ & $\begin{array}{c}\begin{array}{c}\text { Individuals should have good connec- } \\
\text { tivity to each other and to environment } \\
\text { for rapid reconfiguration }\end{array} \\
\end{array}$ \\
\hline Flexibility & $\begin{array}{l}\text { Ability of a system to change status } \\
\text { within an existing configuration [16] }\end{array}$ & $\begin{array}{c}\text { Individuals should be able to connect } \\
\text { and adapt to each other to provide flexi- } \\
\text { ble solution }\end{array}$ \\
\hline Resilience & \begin{tabular}{|c|}
$\begin{array}{c}\text { Ability of a system to return to its origi- } \\
\text { nal state or move to a new, more desira- } \\
\text { ble state after being disturbed [16] }\end{array}$ \\
\end{tabular} & $\begin{array}{l}\begin{array}{l}\text { SoLS should be able to dynamically self- } \\
\text { reconfigure to adapt to unpredictable and } \\
\text { disruptions }\end{array} \\
\end{array}$ \\
\hline $\begin{array}{l}\text { Sustainabil- } \\
\text { ity }\end{array}$ & $\begin{array}{c}\text { Ability of a system to protect, sustain } \\
\text { and enhance the human and natural } \\
\text { resources that will be needed in the } \\
\text { future while meeting a desired goal [17] }\end{array}$ & $\begin{array}{l}\text { SoLS should function on the basis of } \\
\text { common goal of sustainability, by pro- } \\
\text { tecting human and natural resources }\end{array}$ \\
\hline
\end{tabular}

\subsection{Related Concepts and Paradigms}

Before illustrating the features and functions of SoLS, it is necessary to provide consensual definition to the emerging concepts and paradigms used in this paper. The related concepts and paradigms are classified here according to their objective: conceptual criteria, technical paradigm, technology and application. Table 2 gives a short description from the literature adapted for the purpose of this paper.

Table 2. Concepts and paradigms related to SoLS

\begin{tabular}{l|l}
\hline Classes & Short description \\
\hline Conceptual & $\begin{array}{l}\text { Openness: system boundary is unset but variable and flexible [4]. } \\
\text { Adaptation: objects adapt to each other for coordination of activities and to leads } \\
\text { to more efficient processes [18]. } \\
\text { Reconfiguration: add, remove and modify logistics activities and functions [19]. } \\
\text { Criteria }\end{array}$ \\
$\begin{array}{l}\text { ager-organisation: a system can function without significant intervention by man- } \\
\text { agers, engineers, or software control [8]. }\end{array}$ \\
\hline Technical & $\begin{array}{l}\text { Cyber-Physical System: integrations of computation with physical processes [3]. } \\
\text { Intelligent and active products: a product able to self-identify its state, and able } \\
\text { Paradigm }\end{array}$ \\
\hline
\end{tabular}




\begin{tabular}{l|l}
\hline & $\begin{array}{l}\text { Multi-agents System: system to coordinate intelligent behaviour among a group of } \\
\text { agents which are autonomous and flexible computational systems [21]. } \\
\text { Holonic System: a system composed of holons. Holons are autonomous, cooperat- } \\
\text { ing and potentially recursive decisional entities, which can simultaneously be part } \\
\text { or sub-whole of the system. A holon is most of the time composed of a physical } \\
\text { part along with a digital one [22]. } \\
\text { Complex Adaptive System: a system that emerges over time into a coherent form, } \\
\text { and adapts and organises itself without any singular entity deliberately managing or } \\
\text { controlling it [11]. }\end{array}$ \\
\hline Technology \\
$\begin{array}{l}\text { IoT: Internet of Things is the network of physical objects that are connected via } \\
\text { Internet and technologies providing unique addressing schemes, such as RFID tags, } \\
\text { sensors etc. [23] } \\
\text { ICT: Information and communications technology for the communication between } \\
\text { objects or systems [24] } \\
\text { Embedded systems: combination of computer hardware and software, and perhaps } \\
\text { additional mechanical or other parts, designed to perform a dedicated function } \\
\text { inside a single identified system [25]. }\end{array}$ \\
$\begin{array}{l}\text { Intelligent logistics: a will to plan, manage or control logistics activities in a more } \\
\text { Application } \\
\text { intelligent way [1]. It may rely on intelligent products, data techniques etc. } \\
\text { Physical Internet: the network of logistics networks using the internet analogy [4]. }\end{array}$ \\
\hline
\end{tabular}

After this short literature review, the next section introduces specifications of the SoLS.

\section{$3 \quad$ Specifying Self-organising Logistics System}

To construct an effective and efficient SoLS, and to avoid some unexpected or undesirable outcomes, we propose several functionalities for the system. This part discusses three that are identified as crucial factors: openness, intelligence and decentralised control.

\subsection{Openness}

Openness in SoLS means the boundary of the system is unset and open so that individual (actors, assets, supply chain, etc.) can easily join and leave the system. An illustrative example can refer to connecting a computer to the Internet from all over the world for different purpose, like searching information or communicating with others. Individuals join the SoLS to provide, procure or share logistics assets (truck, facilities etc.) and logistics service (delivering, planning etc.). By that, SoLS becomes fast extendable and reducible to answer highly flexible logistics requirements, as shown Fig. 1. Here we discuss several functions that are essential to this end.

Function 1.1 Connectivity: this function means that individual can easily connect with others or and the environment. For example in Fig. 1, individuals outside can easily connect to the system or other individuals within, if rules and standards are respected. System-wide modularisation and standardisation of physical assets (e.g. Physical Internet Container [20]), information systems (e.g. ICT) and organisation 
models is crucial to enable good connectivity. Examples can refer to Physical Internet $[4,26]$. Notions of interoperability must equally be considered to allow an adequate communication between the different actors.

Function 1.2 Reconfiguration: Once the system receives new logistics requests (transport, stocking etc.), it should be able to add or change some current functions inside to fulfil the requests. The reconfiguration function is particularly important to cope with disruptions, i.e. the system can rapidly self-reconfigure [27].

Function 1.3 Adaptation: individuals should adapt to each other and to environment, in order to rapidly build up effective and efficient coordination between them [11].

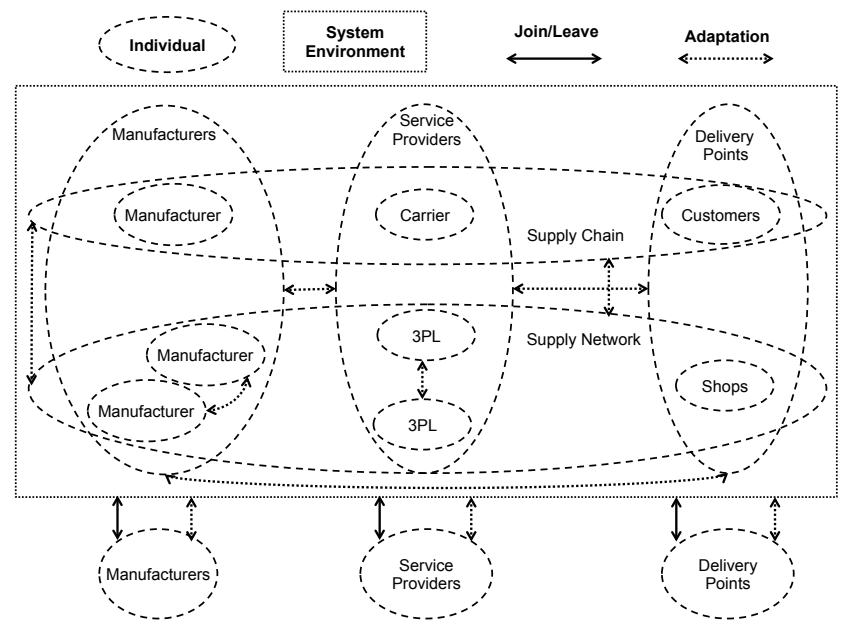

Fig. 1. Open logistics system

\subsection{Intelligence}

Intelligence in SoLS means that every individual within the system is able to make and execute autonomous decision, and to interact with other individuals and with the environment. For that, they should have the ability to collect, store and process information from other individuals (their state and decision) and from environment (rule modification). We propose that IoT technology is a fundamental support to such requirements. Further, two important functions are identified for such a functionality.

Function 2.1 Activeness: individuals should have to ability to collect information from other individuals (their state and decision) and from environment (rules and any modifications), then to store and process the information for autonomous decisionmaking. Further, they should also be able to send information to others, to advertise the changes of their state and to take decision. Each event can be seen as a change to the system, e.g. a warehouse is disrupted, a truck is full, or an order is cancelled. Activeness is therefore an important functionality for SoLS. 
Function 2.2 Autonomous acting: once a decision has been made, systems should also be able to apply and execute the decision. This function could be relying on embedded systems of autonomous operating assets, autonomous supply chain or autonomous network, including sensors and actuators inside decisional loops.

Fig. 2 illustrates some existing and emerging examples of intelligence applied in logistics. It is obvious that some of the three functions are questionable under current organisation and technologies in logistics. However, emerging innovative technologies may help us to project the future of intelligence in SoLS, e.g. drone, autonomous operating truck, or Kiva.

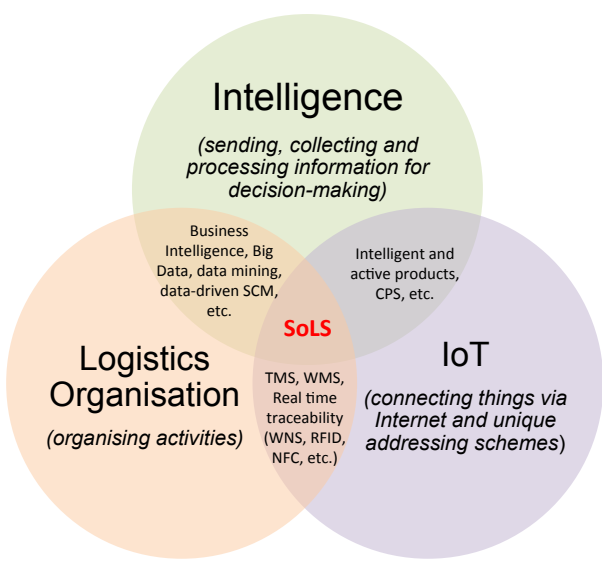

Fig. 2. Technologies and Techniques of intelligence applied in logistics

\subsection{Decentralised Control}

As stated in [11], "imposing too much control in a complex system detracts from innovation and flexibility; conversely, allowing too much emergence can undermine managerial predictability and work routines". In this paper we propose to specify SoLS as rule-based decentralised control system, for the sake of effectiveness and efficiency [28]. More precisely, rule-based decentralised control in SoLS aims to help the autonomous decision-making of individuals within the system. It has a twofold objective: to avoid unpredictable and undesirable outcomes, and to lead individuals towards a system-wide common goal. We propose that decentralised control should rely on system-wide well-designed rules and individual-wide protocols, which should be respected when local autonomous decisions occur [28]. In such a context, we propose that the decentralised control in SoLS should be modelled as a holonic and multi-agent system [7,21], with the following functions:

Function 3.1 Holonic multi-agent system: we propose to model SoLS as holonic multi-agents system (HMAS), since controlling in such a system should be at individual level, i.e. at holon level (whole, part, or sub-whole). Each holon is composed of a physical part mirrored by an agent in the model. Each agent is self-controlling so that no controlling agent is necessary in the HMAS. 
Function 3.2 Rule- and protocol-based: rules here represent the common regulations of the system that every individual should respect; and protocols stand for communication protocols that allow individual communicate to each other, i.e. interoperability. Take digital internet as an example, in which rules are law and protocol is internet protocol like TCP/IP. In other words, rules are designed for meeting common goal; and protocols for effective and efficient communication.

Fig. 3 presents system architecture of rule- and protocol-based HMAS. We consider here a transport request as an example of logistics activities. As per current organisation, driver (P1) and transportation means (P2) are essential for it. In SoLS scenario, a HMAS model is employed to help P1 and P2 to make decisions. More precisely, each of P1 and P2 is mirrored by an agent in the MAS model. Rules of logistics organisation (e.g. speed limit, preconizing multi-modal transport, etc.) and protocols between objects (e.g. driving instruction, autonomous driving control etc.) are translated as the environment of the MAS model. By that, P1 (or V1) and P2 (or V2) should respect the environment when they make autonomous decisions. The MAS model here thus aims to coordinate and cooperate the agents - physical objects, but not to control.

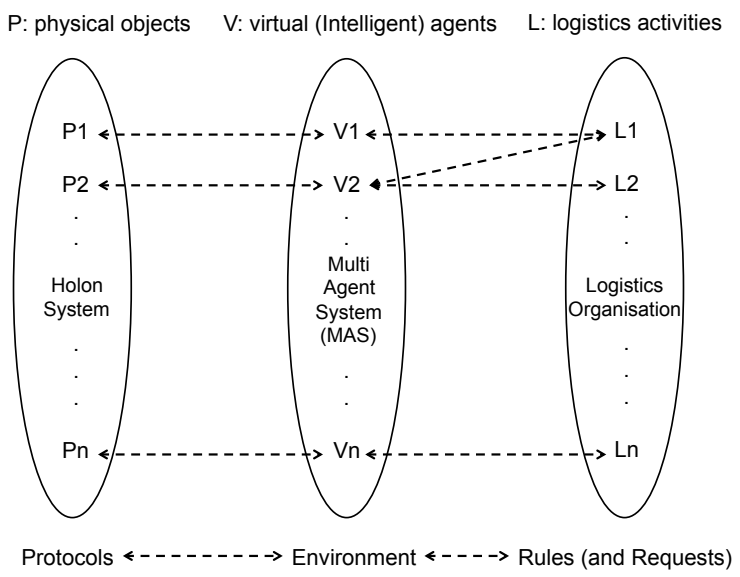

Fig. 3. Modelling SoLS as rule- and protocol-based holonic multi-agent system

\section{Conclusion}

This paper aims to contribute to specify advantages and functionalities of selforganising logistics system (SoLS), which is a novel paradigm in logistics. Openness, intelligence and decentralised control are the three main functionalities proposed and discussed in this paper as vital functionalities of SoLS to cope with the current and future challenges in logistics. Real world examples can refer to the recent DHL research project - Parcelcopter SkyPort ${ }^{1}$. Basically, the idea is to conjointly use autonomous drones (Parcelcopter) and automated parcel stations (Packstations) to cope

\footnotetext{
${ }^{1}$ http://www.dpdhl.com/en/media_relations/specials/parcelcopter.html
} 
with demanding logistics challenges such as "same day delivery", especially in rural zones. Drones and Packstations together can be seen as a SoLS. Once a package to be delivered is arrived at Packstation with known constraints (volume, delivery location and time etc.), the system will autonomously plan and optimise the delivery. Only monitoring is necessary from outside. We may assume that, supported by the emerging technologies and techniques, more and more examples of SoLS would be found and realised.

The paper provides also an insightful overview and theoretical framework for the future work. For example, organisational and technical issues related to SoLS, such as protocol design, coordination or security issues, can be investigated through mechanism design theory for example. Quantitative researches through simulation and optimisation approaches are also necessary to investigate the performance and viability of SoLS in real-life cases.

\section{Acknowledgement}

The authors like to thank the French National Research Agency (ANR) for the support to Project PI-NUTS (ANR-14-CE27-0015).

\section{Reference}

1. McFarlane, D., V. Giannikas, and W. Lu, Intelligent logistics: Involving the customer. Computers in Industry, 2016.

2. Barbosa, J., et al., Dynamic self-organization in holonic multi-agent manufacturing systems: The ADACOR evolution. Computers in Industry, 2015. 66: p. 99-111.

3. Lee, E.A. Cyber physical systems: Design challenges. in Object Oriented Real-Time Distributed Computing (ISORC), 2008 11th IEEE International Symposium on. 2008. IEEE.

4. Ballot, E., B. Montreuil, and R. Meller, The Physical Internet: The Network of Logistics Networks. 2014: La documentation Française.

5. Serugendo, G.D.M., et al., Self-organisation: Paradigms and applications. 2003: Springer.

6. Aliu, O.G., et al., A survey of self organisation in future cellular networks. Communications Surveys \& Tutorials, IEEE, 2013. 15(1): p. 336-361.

7. Serugendo, G.D.M., M.-P. Irit, and A. Karageorgos, Self-organisation and emergence in MAS: An overview. Informatica, 2006. 30(1).

8. Bartholdi Iii, J.J., D.D. Eisenstein, and Y.F. Lim, Self-organizing logistics systems. Annual Reviews in Control, 2010. 34(1): p. 111-117.

9. Sallez, Y., The Augmentation Concept: How to Make a Product "Active" during Its Life Cycle, in Service Orientation in Holonic and Multi-Agent Manufacturing Control, T. Borangiu, A. Thomas, and D. Trentesaux, Editors. 2012, Springer Berlin Heidelberg: Berlin, Heidelberg. p. 35-48.

10. Wycisk, C., B. McKelvey, and M. Hülsmann, "Smart parts" supply networks as complex adaptive systems: analysis and implications. International Journal of Physical Distribution \& Logistics Management, 2008. 38(2): p. 108-125.

11. Choi, T.Y., K.J. Dooley, and M. Rungtusanatham, Supply networks and complex adaptive systems: control versus emergence. Journal of Operations Management, 2001. 19(3): p. 351-366. 
12. Hülsmann, M., et al. Autonomous Cooperation-A Way to Cope with Critical Incidents in International Supply Networks (ISN)? An Analysis of Complex Adaptive Logistic Systems (CALS) and their Robustness. in 24th EGOS Colloquium, Upsetting Organizations, webpublication. 2008.

13. Bousbia, S. and D. Trentesaux. Self-organization in distributed manufacturing control: state-of-the-art and future trends. in Systems, Man and Cybernetics, 2002 IEEE International Conference on. 2002. IEEE.

14. Narahari, Y., et al., Game Theoretic Problems in Network Economics and Mechanism Design Solutions. 2009, London: Springer.

15. Mentzer, J.T. and B.P. Konrad, An efficiency/effectiveness approach to logistics performance analysis. Journal of business logistics, 1991. 12(1): p. 33-62.

16. Bernardes, E.S. and M.D. Hanna, A theoretical review of flexibility, agility and responsiveness in the operations management literature: Toward a conceptual definition of customer responsiveness. International Journal of Operations \& Production Management, 2009. 29(1): p. 30-53.

17. Labuschagne, C., A.C. Brent, and R.P. Van Erck, Assessing the sustainability performances of industries. Journal of cleaner production, 2005. 13(4): p. 373-385.

18. Jahre, M. and N. Fabbe-Costes, Adaptation and adaptability in logistics networks. International Journal of Logistics: Research and Applications, 2005. 8(2): p. 143-157.

19. Koren, Y., et al., Reconfigurable manufacturing systems. CIRP Annals-Manufacturing Technology, 1999. 48(2): p. 527-540.

20. Sallez, Y., et al., On the activeness of intelligent Physical Internet containers. Computers in Industry, 2016. 81: p. 96-104.

21. Botti, V. and A.G. Boggino, ANEMONA: A multi-agent methodology for Holonic Manufacturing Systems. 2008: Springer Science \& Business Media.

22. Giret, A. and V. Botti, Holons and agents. Journal of Intelligent Manufacturing, 2004. 15(5): p. 645-659.

23. Atzori, L., A. Iera, and G. Morabito, The Internet of Things: A survey. Computer Networks, 2010. 54(15): p. 2787-2805.

24. Shen, W., et al., Applications of agent-based systems in intelligent manufacturing: An updated review. Advanced Engineering Informatics, 2006. 20(4): p. 415-431.

25. Barr, M. Embedded Systems Glossary. Neutrino Technical Library. Retrieved 2007-04-21. 2007.

26. Montreuil, B., Toward a Physical Internet: meeting the global logistics sustainability grand challenge. Logistics Research, 2011. 3(2-3): p. 71-87.

27. Kim, Y., Y.-S. Chen, and K. Linderman, Supply network disruption and resilience: A network structural perspective. Journal of Operations Management, 2015. 33-34(0): p. 4359.

28. Bakule, L., Decentralized control: An overview. Annual Reviews in Control, 2008. 32(1): p. 87-98. 